\title{
INOVASI TEKNOLOGI PENGOLAHAN GAMBIR DAN KAJIAN SNI 01-3391-2000
}

\author{
Gambir Processing Technology Innovation and Study of SNI 01-3391-2000
}

\author{
Amos Lukas 1), Suharto Ngudiwaluyo 1), Heru Mulyono ${ }^{2)}$ dan Himawan Adinegoro ${ }^{3)}$ \\ 1) Pusat Sistem Audit Teknologi BPPT, PUSPIPTEK Tangerang Selatan, Banten, Indonesia \\ 2) Pusat Teknologi Kawasan Strategis dan Sistem Inovasi BPPT, Tangerang Selatan, Banten, Indonesia \\ 3) Pusat Teknologi Agroindustri BPPT, PUSPITEK Tangerang Selatan, Banten, Indonesia \\ Email: yeremia2002@yahoo.com,
}

\begin{abstract}
Abstrak
Pengolahan gambir di Propinsi Sumatera Barat yang tersebar di pedesaan menghasilkan mutu gambir yang berbeda. Untuk menghasilkan mutu yang sama perlu adanya acuan mutu berdasarkan harga jual gambir. Badan Standardisasi Nasional bersama Pemerintah Daerah Sumatera Barat dan Asosiasi petani gambir melakukan standardisasi gambir yang dihasilkan dari berbagai petani mengacu SNI 01-3391-2000. Hasil penelitian Thorpe and Whiteley dan permintaan kandungan katekin gambir oleh konsumen ada yang berbeda dengan SNI 01-3391-2000, untuk itu perlu terus melakukan inovasi proses pengolahan gambir untuk memenuhi mutu gambir sesuai hasil penelitian Thorpe and Whiteley yang saat ini dibutuhkan konsumen. Harga jual gambir tidak ditentukan oleh tinggi atau rendahnya kandungan katekin tapi lebih kepada memenuhi standar katekin permintaan konsumen. Harga gambir dengan kandungan katekin 25-35\% lebih tinggi dari pada katekin 80\%. Kajian ulang terhadap SNI 01-3391-2000 gambir perlu segera dilakukan agar penentuan mutu gambir juga didasarkan pemanfatannya dan bukan hanya pada kandungan katekin pada produk gambir.
\end{abstract}

Kata Kunci: SNI 01-3391-2000, gambir, katekin, teknologi pengolahan, mutu.

\begin{abstract}
Gambier processing in West Sumatra Province which is spread in rural areas and produces different quality gambier. To produce the same quality it is necessary to have a quality reference based on the selling price of gambier. The National Standardization Agency with the West Sumatra Regional Government and the Gambir Farmers Association conducts the standardization of gambier produced by various farmers, referring to SNI 01-3391-2000. The results of Thorpe and Whiteley research and the demand for gambier catechin content by consumers are different from those specified in SNI SNI 01-3391-2000, therefore it is necessary to continue to innovate the gambier processing to fulfill the quality of gambier according to Thorpe and Whiteley's research that are currently needed by consumers. The selling price of gambier is not determined by the high or low content of catechins, but rather the catechin standards of consumer demand. Gambir prices with catechin content $25-35 \%$ higher than catechin $80 \%$ catechin. A review of SNI 01-3391-2000 gambier needs to be done immediately so that the determination of gambier quality is also based on its utilization and not only on the catechin content of gambier products.
\end{abstract}

Keywords: SNI 01-3391-2000, gambier, catechins, technology proces, quality.

\section{PENDAHULUAN}

Gambir merupakan sari getah yang diperoleh dari hasil ekstrak daun dan ranting tanaman gambir (Uncaria gambir Roxb) yang dikeringkan. Pengolahan produksi gambir dilakukan dengan peralatan dan cara tradisional di kepulauan Melayu pada pertengahan abad ketujuh belas, yaitu di Sumatra dan di bagian barat Jawa dan Semenanjung Malaya. Awalnya digunakan sebagai obat dan dikunyah dengan sirih. Di Indonesia dalam produksi gambir pertama kali di daerah Riau (Trocki, 2007).
Puncak perdagangan gambir di Singapura adalah pada 1830 -an hingga 1850 -an, didorong oleh permintaan dari industri pencelupan dan penyamakan kulit Inggris (Thulaja, 2003)

Diplomat Edmund Roberts mencatat bahwa pada kunjungannya ke China pada 1830an, orang-orang Cina menggunakannya gambir untuk penyamakan kulit, oleh sebab kandungan katekinnya tidak membuat kulit busuk dan keropos dan dimanfaatkan untuk kesehatan yang dikunyah bersamaan dengan pinang (Roberts, 1837).

Pada tahun 1860 hingga 1880, produksi gambir diperluas di dekat Johor (Jackson, 
1968). Kandungan katekin gambir yang diteliti oleh Thorpe and Whiteley (1921) dan Amos (2018) adalah sebesar 7 - $33 \%$, Gambir yang diproduksi secara komersial kandungan katekin kurang dari $20 \%$ hingga lebih dari $40 \%$ tergantung pada pemanfaatannya (Richard dkk 1992, Amos, 2018).

Tanaman gambir saat ini hanya terdapat di Indonesia dan tersebar di Propinsi yang terletak di Pulau Sumatera, yaitu Propinsi Daerah Istimewa Aceh, Propinsi Sumatera Selatan, Propinsi Bangka Belitrung, Propinsi Sumatera Utara, Propinsi Sumatera Barat, Propinsi Riau dan Propinsi Riau Kepulauan. (Amos et al. 2004).

Gambir yang dihasilkan dari berbagai sentra produksi diproses dengan pengolahan dan peralatan sesuai dengan kondisi wilayah dan kearifan lokal yang dimiliki, sehingga masing masing sentral produksi menghasilkan mutu yang berbeda dengan pasar yang berbeda. (Amos, 2010). Produksi gambir di Sumatera Barat data tahun 2018 mencapai 1000 ton perbulan yang dihasilkan dari 1.700 rumah kempa (sentral produksi) yang tersebar di beberapa kecamatan dan desa di Kabupaten Limapuluh Kota dan Kabupaten Pesisir Selatan, menghasilkan mutu yang berbeda (Dhalimi, 2006). Menurut ketua umum asosiasi komoditi gambir Indonesia bahwa $80 \%$ ekspor gambir berasal dari Sumatera Barat (Elfisha, 2018).

Kandungan katekin yang dihasilkan dari berbagai sentra proses olahan gambir adalah sebesar $2.5 \%$ sampai dengan 95\% (Amos et al, 2004). Gambir yang dihasilkan dengan kadar katekin yang berbeda memiliki pasar yang berbeda dan seusai untuk kebutuhannya sehingga tidak terjadi persaingan pasar antara gambir yang berbeda kandungan katekinnya.

Sejak tahun 1996 sampai saat ini permintaan gambir dengan kandungan katekin 25 - $35 \%$ semakin meningkat jumlahnya dengan harga yang lebih baik dari pada gambir yang berdasarkan mutu SNI. Informasi yang diperoleh dari eksportir dan petani gambir pada awal agustus 2018 harga gambir mutu I SNI sebesar Rp. 19.000 dan harga gambir dengan kadar katekin 25-35\% sebesar Rp. 42.000,-

Penentuan mutu gambir dalam SNI sangat ditentukan oleh kandungan katekin, kadar abu, kadar air dan kadar bahan tak larut dalam air dan alkohol, dan juga mempengaruhi bentuk dan warna. Kandungan utama gambir adalah katekin dan asam kateku tannin (Yeni et al, 2016) dan kadar ketekin menjadi penentu mutu gambir yang ditetapkan dalam SNI 013391-2000 (Andasuryani dkk, 2014). Hasil penelitian Thorpe and Whiteley (1921), menyampaikan bahwa katekin gambir yang di ambil sampelnya adalah sebesar $7-33 \%$, pada faktanya hasil penelitian Thorpe and Whiteley berbeda dengan mutu gambir yang ditetapkan SNI, yaitu katekin $>40 \%$ untuk mutu II dan $>60 \%$ untuk mutu I.

Industri yang menggunakan gambir sebagai bahan aktifnya telah ada sejak awal abab 19, dan pandangan peneliti berdasarkan hasil studi dan survey menggunakan gambir yang diteliti oleh Thorpe and Whiteley oleh sebab itu perlu dilakukan review terhadap SNI gambir yang berlaku saat ini.

Untuk menghasilkan gambir dengan kandungan katekin sebesar 25 - $35 \%$ perlu dilakukan inovasi pengolahan gambir yang dilakukan perubahan mulai dari proses pemilihan daun, perebusan, ekstraksi, pengendapan, pemirisan, pencetakan, dan penjemuran gambir.

Standar gambir sejak abab 19 atas dasar penelitian Thorpe and Whiteley (1921) mendapatkan kandungan katekin 7 - $35 \%$ dan Leung (1980) juga meyampaikan hasil penelitiannya katekin 30-35\%. Kedua peneliti bukan dari daerah penghasil gambir dan diperkirakan sampel gambir diambil dari industri yang ada di sekitarnya.

\section{TINJAUAN PUSTAKA}

\subsection{Gambir}

Gambir adalah sari getah yang diekstraksi dari daun tanaman gambir (Uncaria gambir Roxb) dengan cara pengepresan (Amos et al, 2004). Gambir merupakan salah satu komoditas unggulan Indonesia, karena telah mampu memasok kebutuhan dunia hingga mencapai 80\% (Evalia et al, 2012).

Gambir umumnya mengandung bahan tidak larut alkohol sekitar 34\%, bahan tidak larut air $33 \%$, dan kadar air 15\%. Katekin merupakan senyawa utama gambir (Taniguchi et al (2007); Apea-Bah et al (2009); Anggraini et al (2011).

Ekstrak gambir mengandung beberapa komponen yaitu katekin, asam kateku tanin, quersetin, kateku merah, gambir flouresein, abu, lemak dan lilin. Kandungan utama gambir adalah katekin (7-33 \%) dan asam kateku tannin (20-55\%) (Thorpe and Whiteley, 1921), pada Tabel 1. 
Tabel 1. Komponen kimia dalam gambir

\begin{tabular}{clc}
\hline No. & Nama Komponen & Jumlah (\%) \\
\hline 1. & Katekin & $7-33$ \\
2. & Asam Kateku tanin & $20-55$ \\
3. & Pyrocathecol & $20-30$ \\
4. & Gambir flouresensi & $1-3$ \\
5. & Catechu merah & $3-5$ \\
6. & Quersetin & $2-4$ \\
7. & Fixed oil & $1-2$ \\
8. & Lilin & $1-2$ \\
9. & Alkaloid & sedikit \\
\hline
\end{tabular}

Sumber : Nazir, 2000

Berdasarkan peneliti hasil penelitian Thorpe and Whiteley (1921), Amos et al, 2004 dan Nazir (2000), yaitu kandungan katekin gambir berkisar $7-33 \%$ artinya bila katekin di atas atau di bawahnya adalah bukan katekin dari gambir, hal ini sangat merugikan petani, pengrajin gambir di Indonesia.

Umumnya gambir mengandung tidak lebih dari 34\% bahan tidak larut alkohol, 33\% bahan tidak larut air, dan sekitar $15 \%$ kadar air. Gambir tidak mudah bercampur dengan alkaloid dan gelatin (Martindale, 1982).

Kandungan utama pada gambir d- dan Ikatekin $\left(\mathrm{C}_{15} \mathrm{H}_{14} \mathrm{O}_{6}\right)$ sebanyak $30-35 \%$. Katekin jika mengalami pemanasan lama atau pemasakan dengan larutan bersifat basa karena kondensasi sendiri akan berubah menjadi asam katekutannat (catechutannic acid) yang berjumlah $\pm 24 \%$ (Leung, 1980).

Tanin pada daun gambir termasuk tipe proantosianidin. Daun gambir mengandung katekin yang sedikit larut dalam air dingin, tetapi mudah sekali larut dalam air panas. Tanin ini memiliki khasiat sebagai algisida, juga antibakteri dan antijamur (Lemmens, 1999).

Katekin hidrat (bentuk $\mathrm{d}, \mathrm{L}$ dan $\mathrm{dL}$ ) mempunyai titik leleh $93^{\circ} \mathrm{C}$ dan bentuk anhidridanya mempunyai titik leleh lebih tinggi, yaitu $174-175^{\circ} \mathrm{C}$.

Menurut Thorpe (1922), rumus molekul catechin dalam keadaan "anhydrous" adalah $\mathrm{C}_{15} \mathrm{H}_{14} \mathrm{O}_{6}$. Katekin "anhydrous" mempunyai berat molekul 290.28 dengan komposisi atom C sebesar $62.02 \%$, atom $\mathrm{H}$ sebesar $4.86 \%$ dan atom $\mathrm{O}$ sebesar $33.07 \%$. Katekin yang berasal dari gambir mempunyai rumus $\mathrm{C}_{15} \mathrm{H}_{16} \mathrm{O}_{6} .4 \mathrm{H}_{2} \mathrm{O}$ dengan titik cair pada suhu $175-177^{\circ} \mathrm{C}$.
Rendemen dan mutu gambir tidak hanya dipengaruhi oleh proses penggempaan tetapi juga dipengaruhi oleh kondisi bahan baku. Menurut Burkill (1935), daun gambir muda mempunyai kandungan katekin yang lebih tinggi dibandingkan dengan daun tua.

Pasar membutuhkan gambir dengan kandungan katekin kurang dari 20\% hingga lebih dari $40 \%$ tergantung pada pemanfaatanya. (Richard et al, 1992), sama dengan hasil survey atas permintaan eksportir di Indonesia.

Asam kateku tannin memberikan rasa pahit pada gambir. Asam kateku tannin mempunyai rumus kimia yaitu $\mathrm{C}_{15} \mathrm{H}_{12} \mathrm{O}_{5} \cdot 3 \mathrm{H}_{2} \mathrm{O}$. Apabila katekin dipanaskan pada temperatur $110^{\circ} \mathrm{C}$ atau dengan cara memanaskan pada larutan alkali karbonat, maka akan kehilangan satu molekul air dan berubah menjadi asam kateku tannin. Asam kateku tannin merupakan serbuk berwarna coklat kemerah-merahan, cepat larut dalam air dingin dan alkohol, tidak berwarna dalam larutan timah hitam asetat (Nazir, 2000).

Asam kateku tannin adalah campuran terbesar yang terkandung dalam gambir dan merupakan suatu zat amorf yang larut dalam air dingin. Bila air diuapkan akan tertinggal zat berwarna merah kecoklatan. Larutannya akan memberikan zat warna hijau dengan $\mathrm{Fe}^{3+}$. Sifat inilah yang menunjukkan bahwa tanin yang terdapat dalam gambir merupakan turunan fenol (Amos et al., 2004).

Pyrocathecol disebut juga asam pirocatechoat atau 1,2-dihidroksi benzene dengan rumus kimia $\mathrm{C}_{6} \mathrm{H}_{6} \mathrm{O}_{2}$. Zat ini merupakan hasil penguraian dari zat lain seperti catechin. Pyrocathecol larut dalam air, alkohol, eter, benzene, kloroform dan larut baik pada piridin dengan larutan bersifat basa. Karakteristik pyrocathecol antara lain jika dipanaskan akan membentuk catechol, membentuk warna hijau dengan $\mathrm{FeCl}_{3}$, membentuk endapan dengan brom, larutannya dalam air cepat berwarna coklat, dan dapat mereduksi perak amoniakal dan fehling. Pyrocathecol dapat digunakan sebagai obat diare dan penawar racun (Nazir, 2000).

Gambir flouresensi merupakan bagian kecil dari gambir dan memberikan fllouresensi yang berwarna hijau. Menurut Nazir (2000), flouresensi ini dapat dilihat apabila larutan gambir dalam alkohol dikocok dengan petroleum eter dalam suasana sedikit basa. Pada lapisan petrolium eter akan terlihat perpendaran berwarna hijau. 
Keteku merah (catechu red) yaitu gambir yang memberikan warna merah. Quersetin merupakan zat turunan flavanol yang berwarna kuning dengan rumus kimia $\mathrm{C}_{15} \mathrm{H}_{10} \mathrm{O}_{7}$. Quersetin larut dalam air dan alkohol dan berubah menjadi warna gelap dengan pemanasan (Nazir, 2000).

Fixed oil merupakan minyak yang sukar menguap. Menurut Nazir (2000), fixed oil dapat digunakan sebagai bahan parfum, minyak atsiri dan pewangi makanan. Pada tanaman gambir juga terdapat lilin yang terletak pada lapisan permukaan daun gambir. Lilin merupakan monoester dari suatu asam lemak dan alkohol.

Menurut Nazir (2000), ada tujuh macam alkaloid pada daun gambir yaitu dihidrogambirtaninna, gambirdina, gambirtanina, gambirina, isogambirina, auroparina, oksogambirtanina. Tanin yang terdapat dalam gambir merupakan tanin yang tidak dapat dihidrolisa (tanin kondensasi). Tanin ini merupakan turunan dari flavanol yang tidak dapat dihidrolisa dengan asam ataupun basa.

\subsection{Manfaat Gambir}

Gambir yang mengandung dua komponen utama yaitu katekin dan asam kateku tannin mempunyai banyak manfaat. Selain dipakai sebagai salah satu ramuan makan sirih, gambir juga digunakan sebagai pewarna tekstil, penyamak kulit, antiseptik, bahan pencampur kosmetik, astrigen, pemberi rasa pahit pada bir, campuran obat tradisional dan obat modern (Heyne, 1987).

Perbedaan hasil kandungan katekin ekstrak gambir disebabkan perbedaan dalam pemanfaatannya. Ekstrak Gambir dapat dimanfaatkan sebagai zat penyamak, untuk menyirih, kosmetik dan obat herbal, sehingga untuk tiap kebutuhan akan memerlukan mutu yang berbeda (Isnawati et al, 2012).

Pada industri farmasi, perusahaan dari Swiss melakukan isolasi katekin dari daun gambir yang digunakan untuk penyakit hati dengan nama paten "Catergen". Di India gambir digunakan sebagai lotion dan astringent. $\mathrm{Di}$ Malaysia gambir biasanya digunakan sebagai obat luka bakar. Di Kalimantan digunakan sebagai obat luar untuk sakit kepala. Beberapa contoh kegunaan gambir sebagai obat antara lain obat sariawan, obat sakit kulit, dan obat diare (Hadad et al., 2007).

Sebagai obat-obatan, importir gambir di Jerman Barat mensyaratkan kandungan katekin di dalam gambir sebesar $40-60 \%$. Sebagai bahan penyamak kulit yang dibutuhkan adalah asam kateku tannin dan katekin, dengan kadar tanin minimal $40 \%$ dan kandungan katekin minimal $60.5 \%$ (Maulida, 1985).

Di Jepang gambir dikembangkan sebagai permen pelega tenggorokan khusus untuk perokok karena gambir dapat menetralisir nikotin. Selain itu, gambir juga dikembangkan untuk obat sakit perut dan sakit gigi di Singapura (Nazir, 2000).

Gambir dapat berfungsi sebagai anti diare karena gambir mengandung tanin. Tanin dapat mengendapkan protein sehingga dapat menciutkan mukosa dan membentuk lapisan pada permukaannya untuk melindungi lapisan di bawahnya dari serangan bakteri, iritasi oleh zatzat kimia dan mekanik (Nazir, 2000).

\subsection{SNI Gambir}

Standar Nasional Indonesia SNI 01-3391-2000 adalah hasil revisi dari SNI 01-3391.1994 yang bertujuan untuk: (1) meningkatkan mutu produksi, (2) melindungi konsumen, (3) menunjang ekspor non migas dan (4) mendukung perkembangan indutri agrobisnis gambir,

Standar revisi SNI ini disusun oleh Balai Penelitian dan Pengembangan Industri Padang, Departemen Perindustrian dan Perdagangan, hasil konsensus rapat pada tanggal 25 Nopember 1999.

SNI 01-3391-2000 lebih banyak didasarkan pada produk gambir dari Sumatera Barat, karena $80 \%$ gambir berasal dari Sumatera Barat untuk memenuhi permintaan pasar ekspor.

Syarat mutu hasil revisi tertera pada table 2 sebagai berikut: 
Tabel 2. Syarat Mutu gambir hasil revisi

\begin{tabular}{|c|c|c|c|c|}
\hline \multirow{2}{*}{ No } & \multirow{2}{*}{ Jenis Uji } & \multirow{2}{*}{ Satuan } & \multicolumn{2}{|c|}{ Persyaratan } \\
\hline & & & Mutu 1 & Mutu 2 \\
\hline 1 & $\begin{array}{l}\text { Keadaan } \\
\text { - bentuk }\end{array}$ & - & utuh & utuh \\
\hline & - warna & - & $\begin{array}{l}\text { kuning } \\
\text { sampai } \\
\text { kuning } \\
\text { kecoklat } \\
\text { coklatan }\end{array}$ & $\begin{array}{l}\text { Kuning } \\
\text { kecoklata } \\
\text { n sampai } \\
\text { kuning } \\
\text { kehitam } \\
\text { hitaman }\end{array}$ \\
\hline & - bau & - & khas & khas \\
\hline 2 & $\begin{array}{l}\text { Kadar air, } \\
\mathrm{b} / \mathrm{b}\end{array}$ & $\%$ & maks. 14 & maks. 16 \\
\hline 3 & $\begin{array}{l}\text { Kadar } \\
\text { abu, b/b }\end{array}$ & $\%$ & maks. 5 & maks. 5 \\
\hline 4 & $\begin{array}{l}\text { Kadar } \\
\text { Katekin, } \\
\text { bb adbk }\end{array}$ & $\%$ & $\min 60$ & Min 40 \\
\hline 5 & $\begin{array}{l}\text { Kadar } \\
\text { bahan tak } \\
\text { larut } \\
\text { dalam } \\
\text { - Air b/b } \\
\text { adbk } \\
\text { - Alkohol } \\
\text { adbk }\end{array}$ & $\begin{array}{l}\% \\
\%\end{array}$ & $\begin{array}{l}\text { maks } 7 \\
\text { maks } 12\end{array}$ & $\begin{array}{l}\text { maks } 10 \\
\text { maks } 15\end{array}$ \\
\hline
\end{tabular}

\section{METODE PENELITIAN}

Metode penelitian dilakukan melalui pendekatan kualitatif, dengan cara mengumpulkan data yang berasal dari wawancara, catatan lapangan, dokumen pribadi, catatan, memo, hasil kajian proses dan analisa kimia yang dilakukan oleh peneliti serta dokumen resmi lainnya yang berhubungan dengan tulisan ini. Tujuan dari penelitian kualitatif agar penulis ingin menggambarkan realita empiric dibalik fenomena secara mendalam, rinci dan tuntas dalam menentukan standar produk gambir di Indonesia.

Analisa kandungan katekin dilakukan di laboratorium Sucofindo sekaligus sebagai acuan kadar katekin yang dibutuhkan konsumen. Data yang diperoleh dari wawancara dilakukan pada kurun waktu antara tahun 1998, 2000, 2017 dan 2018 dan pengumpulan data survey peneliti telah dilakukan dari tahun 1992 sampai dengan 2018.

\section{HASIL DAN PEMBAHASAN}

\subsection{Inovasi Teknologi Pengolahan Gambir untuk memenuhi Permintaan Konsumen}

Kebutuhan gambir dengan kadar katekin 25 $35 \%$ menjadi acuan permintaan eksporir PT. Kondo Indonesia untuk memenuhi permintaan industri pangan sehat dari perusahaan PT. Jintan di Jepang, beberapa perusahaan pangan sehat dan obar herbal dari negeri Tiongkok juga meminta katekin dengan kandungan yang sama. Perusahaan obat herbal di Singapura yang menghasilkan obat untuk sakit gigi dan gangguan perut membutuhkan gambir dengan kandungan 25 - 35\%.

Permintaan konsumen langsung ke Indonesia untuk memenuhi katekin dengan kadar katekin 25-35 \% dilakukan sejak tahun 1997, setelah beberapa peneliti Indonesia mempublikasikan hasil penelitian pada jurnal nasional maupun internasional. Oleh sebab itu perlu segera dilakukan inovasi proses pengolahan gambir agar dapat memenuhi permintaan konsumen gambir dan dengan harga yang lebih baik dari pada yang biasa diproduksi atas dasar mutu SNI.

Proses pengolahan gambir untuk memperoleh gambir dengan kandungan katekin $25-25 \%$ dilakukan sebagai berikut:

- Daun dan ranting tua dipetik (Burkill, 1935), dipotong-potong selanjutnya direbus dalam kancah yang berbentuk persegi empat dengan ukuran panjang 3 meter, lebar 1,2 meter dan ketinggian 2,5 meter, perebusan dilakukan sambil mengaduk dengan menggunakan peralatan mekanik yang dijalankan maju mundur selama 2 jam.

- Daun dan ranting diangkat, dan perebusan diteruskan sampai air rebusan (hasil ekstraksi) menjadi kental.

- Hasil perebusan dituang ke dalam ember plastik, 30 menit kemudian diaduk hingga hasil ekstraksi mencapai suhu kamar.

- Dimasukkan dalam cetakan yang berbentuk segiempat besar terbuat dari papan balok dan diendapkan selama 1 malam.

- Keesokan hari cetakan dibuka dan dipotongpotong dengan ukuran $3 \mathrm{~cm} \times 3 \mathrm{~cm} \times 2 \mathrm{~cm}$.

- Ekstrak gambir diletakkan dalam tampi yang terbuat dari rotan, dimasukkan dalam ruangan pengering dan dikeringkan dengan cara mengalirkan udara panas yang didapat 
dari pembakaran kayu ke dalam ruangan pengering.

- Setelah 14 hari produk gambir siap dipasarkan.

SNI 01-3391-2000, membagi mutu gambir atas dasar katekin minimum $40 \%$ untuk mutu 2 dan katekin minimum $60 \%$ untuk mutu 1 tidak relevan dengan hasil penelitian yang sudah dipublikasikan Thorpe and Whiteley (1921), yaitu kandungan katekin antara $7-33 \%$, Amos, 2010 melaporkan bahwa kandungan katekin dari senta gambir di Indonesia 2,5 $95 \%$, kondisi tersebut berbeda dengan mutu gambir SNI.

Tabel 3. Kandungan Ketekin SNI dan Thorpe and Whiteley (1921)

\begin{tabular}{llll}
\hline Kandungan & Mutu I & Mutu II & Thorpe dkk \\
\hline Katekin & $<60 \%$ & $<40 \%$ & $7-33 \%$ \\
\hline
\end{tabular}

Richard dkk (1992), menyatakan bahwa pasar membutuhkan gambir dengan kandungan katekin kurang dari 20\% hingga lebih dari $40 \%$. Permintaan dari PT Kondo Indonesia untuk perusahaan PT. Jintan Jepang adalah gambir dengan katekin 25-35\%, sejak mengetahui bahwa Indonesia memiliki sentra gambir pada tahun 1997 untuk industri pangan sehat PT Jintan di Jepang.

Industri pangan sehat yang telah lama berkembang di Jepang, Tiongkok dan India dalam formulasinya menggunakan katekin pada kadar 25-35\%. Berdasasrkan survey pasar yang dilakukan dari tahun 1997 - 2000, negara Tiongkok mengimpor gambir dengan kandungan $25-35 \%$ dari India.

SNI 01-3391-2000 yang digunakan sebagai acuan mutu gambir atas kandungan gambir mutu I dan Mutu II tidak relevan dengan kebutuhan permintaan konsumen untuk produksi pangan sehat dan kebutuhan indsutri penyamakan kulit.

Pada awal tahun 1990, produksi permen di Tangerang dengan membeli bahan baku gambir dari Tiongkok, setelah mengetahui bahwa gambir dihasilkan di Indonesia maka perusahaan membeli gambir dari Sumatera Barat untuk di reproses menghasilkan katekin sesuai kandungan yang dibutuhkan, dengan cara membeli gambir hasil pres yang masih tinggi kandungan airnya dan katekin di atas 40
\%. Akibatnya gambir mengalami kerusakan selama dalam perjalanan sehingga akhirnya perusahaan menutup industrinya karena tidak memperoleh bahan baku gambir dengan kandungan katekin yang dibutuhkan yaitu 25$35 \%$.

4.2. Inovasi Pengolahan Gambir Katekin 25$35 \%$, seusi dengan Thorpe and Whiteley (1921) dan permintaan konsumen

Kandungan katekin dari daun dan ranting yang tua lebih rendah dari pada daun dan ranting yang muda (Sa'id et al, 2009). Perebusan diatas $110^{\circ} \mathrm{C}$ akan mengubah katekin dan menjadi asam kateku tannin. Kandungan katekin dan asam kateku tannin pada gambir akan saling bertolak belakang. Pada saat katekin tinggi berarti asam kateku taninnya tinggi begitu juga sebaliknya.

Semakin lama perebusan pada suhu 110 ${ }^{\circ} \mathrm{C}$ akan semakin mengurangi kandungan katekin dan perlu diatur waktu yang tepat agar produk gambir sesuai dengan permintaan konsumen. Perlakukan memotong daun dan ranting dalam ukuran $10-15 \mathrm{~cm}$ akan mempercepat terjadinya proses ekstraksi gambir dikarenakan bertambahnya luas permukaan. Mengunakan air baru dalam setiap proses mengurangi kadar abu, proses pengeringan di dalam gubuk pemanasan yang dialirkan udara panas akan mengurangi kadar air yang terkandung di dalamnya.

Pada volume yang sama gambir dengan katekin tinggi bila dibandingkan gambir dengan katekin yang rendah maka gambir katekin tinggi beratnya lebih ringan dari pada gambir katekin rendah. Inovasi teknologi pengolahan gambir agar berhasil harus memperhatikan kearifan lokal yang ada. Hasil gambir yang diperoleh adalah sebagai berikut (Tabel 5).

Tabel 4. Analisa Gambir dari PT Sucofindo

\begin{tabular}{|c|c|c|c|}
\hline No & Jenis Uji & Satuan & $\begin{array}{c}\text { Hasil } \\
\text { Pengamatan }\end{array}$ \\
\hline \multirow[t]{4}{*}{1} & Keadaan & & \\
\hline & - bentuk & - & $\begin{array}{l}\text { Utuh, struktur } \\
\text { teratur dan } \\
\text { tidak rapuh }\end{array}$ \\
\hline & - warna & - & $\begin{array}{l}\text { Luar hitan } \\
\text { dalam kuning } \\
\text { kecoklatan }\end{array}$ \\
\hline & - bau & - & $\begin{array}{l}\text { Khas, ada } \\
\text { bau tannin }\end{array}$ \\
\hline 2 & Kadar air, b/b & $\%$ & $<5 \%$ \\
\hline
\end{tabular}




\begin{tabular}{llcc}
\hline 3 & Kadar abu, b/b & $\%$ & $<1 \%$ \\
\hline 4 & $\begin{array}{l}\text { Kadar Katekin, } \\
\text { bb adbk }\end{array}$ & $\%$ & $27-30 \%$ \\
\hline 5 & $\begin{array}{l}\text { Kadar bahan tak } \\
\text { larut dalam }\end{array}$ & & \\
& - Air b/b adbk & $\%$ & $<2 \%$ \\
& - Alkohol adbk & $\%$ & - \\
\hline
\end{tabular}

\subsection{Kajian SNI 01-3391-2000}

SNI 01-3391-2000, yang bertujuan untuk: (1) meningkatkan mutu produksi, (2) melindungi konsumen, (3) menunjang ekspor non migas dan (4) mendukung perkembangan industri agro bisnis gambir, belum mencapai hasil yang maksimal karena tidak sesuai dengan kebutuhan pasar yaitu katekin $25-35 \%$ untuk pangan sehat dan katekin $7-20 \%$ untuk industri penyamakan dan penjernih bir yang telah berkembang sejak pertengahan abad 17.

Metode pengukuran kandungan katekin dalam gambir berdasarkan pada SNI 01-33912000 (Muchtar et al., 2008). Harga jual eksport gambir pada tanggal 2 Agustus 2018, gambir dengan mutu I (<60\%) sebesar Rp. 19.000/kg dan harga gambir dengan katekin yang lebih rendah (25 - $35 \%$ ) sebesar Rp. 42..000/kg.

Perlu dilakukan rumusan baru untuk SNI 01-3391-2000 dengan mempertimbangkan hasil penelitian Thorpe and Whiteley (1921), kebutuhan pasar (Richard dkk, 1992) dan permintaan konsumen untuk kebutuhan pangan sehat dan industri yang menggunakan gambir dengan kandungan katekin yang berbeda dengan yang tercantum pada SNI 01-33912000.

Gambir sudah menjadi salah satu komiditi ekspor yang dihasilkan Indonesia untuk dunia, maka revisi SNI gambir harus menjadi perhatian stateholder industri gambir Indonesia sehingga akan lebih menggairahkan agrobisnis gambir, meningkatkan produksi, kualitas terjamin sesuai permintaan pasar dan kesejahteraan pengrajin gambir akan meningkat.

Menghasilkan kadar katekin sesuai Thorpe and Whiteley (1921), permintan pasar (Richard dkk, 1992) dan permintaan eksportir sejak tahun 1997 harus menjadi perhatian sentra produksi gambir di Indonesia, agar produk yang dihasilkan dapat dibeli dengan harga lebih baik dan semua produksi dapat terjual ke konsumen.

\section{KESIMPULAN DAN SARAN}

SNI 01-3391-2000, berbeda dengan hasil penelitian Thorpe and Whiteley (1921), kebutuhan pasar gambir (Richard dkk, 1992) dan permintaan gambir oleh konsumen serta hasil penelitian kandungan katekin produk gambir berkisar 2,5 - 95\%. SNI 01-3391-2000, perlu dilakukan kajian ulang agar mutu SNI nya lebih diperluas agar memenuhi kadar katekin yang dibutuhkan pasar (produk pangan sehat dan industri). Pengrajin gambir mampu menghasilkan gambir dengan kandungan katekin yang sesuai dengan hasil penelitian Thorpe and Whiteley yang sampai saat ini dibutuhkan untuk pangan sehat yaitu gambir dengan kandungan katekin 25-35\%.

Harga gambir tidak ditentukan tinggi rendahnya kandungan katekin akan tetapi lebih kepada memenuhi standar katekin permintaan konsumen. Proses pengolahan untuk mencapai kadar katekin tertentu lebih efisien dan optimal bila dilakukan pengolahan langsung dari bahan baku daun dan ranting gambir jadi gambir daripada melakukan reproses terhadap gambir dengan mutu yang telah ada.

Saran dari penelitian ini adalah perlu segera melakukan revisi SNI 01-3391-2000 dengan meninjau kembali kandungan katekin berdasarkan hasil penelitian Thorpe and Whiteley (1921). Standar kandungan katekin yang sesuai dengan kebutuhan pasar agar menjadi acuan di dalam penelitian. Revisi SNI agar melibatkan eksportir, produsen gambir dari berbagai Propinsi di Indonesia.

\section{UCAPAN TERIMA KASIH}

Puji syukur kepada Tuhan yang memberikan rahmat dan kemurahan Nya sehingga dapat menyelesaikan tulisan ini atas dasar kajian yang telah dilakukan. Ucapan terima kasih juga disampaikan kepada rekan-rekan peneliti gambir dari Pusat Teknologi Agroindustri - BPPT yang telah bersama melakukan peneniltian dan penerapan teknologi pengolahan gambir di beberapa propinsi di Indonesia. Terima kasih juga kepada petani pengolah gambir di Sumatera Barat dan Riau yang telah banyak membantu di dalam proses penerapan teknologi pengolahan gambir. Dukungan Pemda Sumatera Barat, Riau, Kepulauan Riau, Babel. Kabupaten Aceh Tenggara, Kabupaten Sidikalang dan Sumatera Selatan yang telah 
menjadi mitra peneliti dalam rangka survei, wawancara dan studi yang dilakukan peneliti.

\section{DAFTAR PUSTAKA}

Amos, 2018. Inovasi Teknologi Pengolahan Gambir, Kanius , Yogjakarta.

Amos, 2018 Inovasi Diversifikasi Produk Gambir, Kanisius, Yogjakarta.

Amos, I. Zainuddin, A. Triputranto, B. Rusmandana, dan S. Ngudiwaluyo. 2004. Teknologi Pasca Panen Gambir. BPPT Press, Jakarta.

Amos. 2010. Kandungan katekin gambir sentra produksi di Indonesia. Journal Standarisasi. 12: 149-155.

Andasuryani, YA Purwanto, IW Budiastra dan K Syamsu. 2014. Prediksi Kandungan katekin Gambir (Uncaria gambir Roxb.) dengan Sektroskopi Nir. Jurnal Teknologi Industri Pangan Vol. 24. No.1

Anggraini T, Tai A, Yoshino T, Itani T. 2011. Antioxidative activity and catechin content of four kinds of Uncaria gambir extracts from West Sumatera, Indonesia. Afr J Biochem Res. 5:33-38.

Apea-Bah FB, M Hanafi, RT Dewi, S Fajriah, A Darmawan, N Artanti, $\mathrm{P}$ Lotulung, $\mathrm{P}$ Ngadimang and B Minarti. 2009. Assessment of th DPPH and $\alpha$ glucosidase inhibitory potential of gambier and qualitative identification of major bioactive compound. Journal of Medicinal Plants Research Vol.3(10). 736-757.

Badan Standarisasi Nasional. SNI 01-33912000. Gambir.

Burkill, I.H. 1935. A Dictionary of The Economic Products of The Malay Peninsula. VOI. II. Millbank. London. P. 2198-2204.

Dhalimi, A. 2006. Permasalahan Gambir (Uncaria gambier Roxb.) di Sumatera Barat dan Alternatif Pemecahannya. Perspektif Vol. 5, No. 1:46-59.

Elfisha, M. 2018. Harga gambir anjlok, asosiasi sinyalir ada permainan pihak tertentu. https://www. antaranews. com/ berita/ 695825/ harga- gambir- anjlok- asosiasisinyalir - ada- permainan - pihak-tertentu.

Evalia, NA, EG Sa'id, dan RN Suryana. 2012. Strategi pengembangan agroindustri dan pengkajian nilai tambah gambir di Kabupaten Lima Puluh Kota Sumatera Barat. Jurnal Manajemen \& Agribisnis Vol. 9 No.3: 173-182.

Gumbira-Sa'id E, Syamsu K, Herryandie A, Mardliyati E, Evalia NA. 2010. Kajian perbaikan mutu pada agroindustri skala mikro dan kecil gambir Indonesia. J IImu Pert Indo. 15: 130-136.

Hadad, MA., NR. Ahmad, M. Herman, H. Supriadi dan AM. Hasibuan. 2007. Teknologi Budidaya dan Pengolahan Hasil Gambir. http//balittri.litbang.deptan. go.id/ database/ 19-03-2011

Heyne, K. 1987. Tumbuhan Berguna Indonesia Jilid III. Badan Litbang Kehutanan, Jakarta.

Isnawati, A., M. Raini, O.D Sampurno, D. M.L Widowati dan R. Gitawati, 2012. Karakterisasi Tiga Jenis Esktrak Gambir (Uncaria Gambir Roxb) Dari Sumatera Barat. Buletin Penelitian Kesehatan, Vol. 40 , N0. 4 ha; 201-208, 2012

Jackson, J.C. 1968. Planters and speculators: Chinese and European agricultural enterprise in Malaya, 1786-1921. University of Malaya Press; [sole distributors: Oxford University Press, London, New York].

Lemmens, R.H.M.J. dan N. Wulijarni-Soetjipto. 1999. Sumber Daya Nabati Asia Tenggara, No. 3, Tumbuh-Tumbuhan Penghasil Pewarna dan Tanin. PT Balai Pustaka, Jakarta bekerja sama dengan Prosea Indonesia, Bogor.

Leung, A.Y. 1980. Encyclopedia Common Natural Ingredients Used in Foods, Drugs and Cosmetics. John Willey \& Sons. New York.

Martindale. 1982. The Extra Pharmacopoeia 28th Edition. The Pharmaceutical Press. London.

Maulida, D. 1985. Evaluasi standar mutu gambir. Makalah pada pertemuan Teknis Penerapan Standar XIV (Gondorukem, Biji Pinang, Damar, Gambir). Direktorat Standarisasi dan Pengendalian MutuDepertemen Perdagangan, Jakarta.

Muchtar H, Yusmeiarti, Yeni G. 2008. The effect of type of absorbance in the isolation process of gambier catechin. $\mathrm{J}$ Riset Ind. 2:14-23. 
Nazir, M. 2000. Gambir: Budidaya, Pengolahan dan Prospek Diversifikasinya. Yayasan Hutanku. Padang.

Richard W. Hemingway; Peter E. Laks; Susan J. Branham (30 September 1992). Plant Polyphenols: Synthesis, Properties, Significance. Springer Science \& Business Media. p. 885. ISBN 978-0-30644252-0.

Roberts, E. 1837. Embassy to the Eastern Courts of Cochin-China, Siam, and Muscat. New York: Harper \& Brothers. p. 138.

Taniguchi S, Kuroda K, Doi K, Inada K, Yoshikado N, Yoneda Y, Tanabe M, Shibata T, Yoshida T, Hatano T. 2007. Evaluation of gambir quality based on quantitative analysis of polyphenolic components. Yakugaku Zasshi. 127(8):1291-1300

Thorpe, JF and M.A Whiteley. 1921. Thorpe's Dictionary of Applied Chemistry. Fourth edition, Vol. II. Longmans, Green and Co. London, 434-438

Thorpe, J.F. 1922. A Texbook of Pharmacognose. Bailliare, Trindall and Cassel. London.

Thulaja, N.R. 2003. "Gambier". Singapore Infopedia. National Library Board of Singapore. Retrieved December 28, 2014.

Trocki, C.A. 2007. Prince of Pirates: The Temenggongs and the Development of Johor and Singapore, 1784-1885. NUS Press. pp. 34-35. ISBN 978-9971-69376-3.

Yeni, G., D. Syafruddin, A. Kasim, dan Amos, 2016. Pengujian Kemampuan Daya Samak CXube dan Limbah Cair Gambir Terhadap Mutu Kulit Tersamak. Jurnal Penelitian dan Pengembangan Baristand Industri Padang. Vol6., No 1 Tahun 2016. Padang 
Prosiding PPIS 2019 - Semarang, 11 Oktober 2019, Hal 241-250 